\title{
NEW NARRATIVES IN THE INDIAN LGBTIQ+ COMMUNITY: AN INTERVIEW WITH FILM-MAKER SUKHDEEP SINGH
}

\author{
Regiane Corrêa de Oliveira Ramos \& Jairo Adrián-Hernández \\ Universidade Estadual de Mato Grosso do Sul (Brasil) \& Universidad de La Laguna
}

Regiane Ramos (RR): I became aware of Sukhdeep Singh's documentary on Facebook, on 24 February 2020, as he posted 'the coming soon flyer'. I immediately wrote to him asking for the actual release date and transsexuality in Sikhism (as I am interested in this topic). He promptly replied and then we started exchanging messages. On 3 December 2020, he sent me an email inviting me to watch the online release of the Sab Rab De Bande (We're all God's Creation) on 5 December 2020. After watching it, I invited him for an interview. We had our conversation on February $5^{\text {th }} 2021$ via Google Meet as I was in Brazil and he in India.

Jairo Adrián-Hernández (JAH): Dr. Corrêa de Oliveira Ramos and I have been working closely on transgender communities in India for some time. After she got to know about this documentary, she kindly invited me to participate in translating the script into Spanish. Then we both got in touch with Mr. Singh for a discussion on his film and activism as part of the LGBTIQ+ community himself. My questions here are then a recreation from this interview, which, if interested, is fully disposed at the BrIndARC (BrasilÍndia Associação de Redes de Conhecimento) YouTube channel (28 June 2021). Due to space constrains, some questions have been either shortened or omitted.

Good afternoon, Sukhdeep. First of all, thank you so much for accepting my invitation to talk about the documentary Sab Rab De Bande (We're all God's Creation) and the challenges that LGBTIQ+ Sikhs face.

RR: Who is Sukhdeep Singh? Please tell me a bit about yourself.

SuKHDEer SINGH (SS): I am a gay Sikh person in his early 30 s who is involved in multiple things. I grew up in Kolkata in a Sikh family, and then proceeded to pursue a degree in Engineering from IIT Dhanbad. While in college, I came out and then founded Gaylaxy Magazine, a LGBTIQ+ e-magazine. After graduating, I started working as a software engineer, while parallel running the magazine. I am currently based in Delhi where I am working as a Senior Software Engineer. Gaylaxy is more of a passion project and has completed 10 years. I have recently also finished my first documentary on LGBTIQ+ Sikhs called Sab Rab De Bande (We're all Gods Creation).

RR: Can you describe Punjabi culture? What is it for queer Sikhs?

DOI: https://doi.org/10.25145/j.recaesin.2021.83.16

Revista Canaria de Estudios Ingleses, 83; November 2021, pp. 215-221; ISSN: e-2530-8335 
SS: Punjab culture is hyper-masculine and patriarchal. There is a very macho image of a Punjabi man that exists, and one is supposed to conform to that. Women are expected to follow patriarchal roles, and everyone is expected to conform to gender roles. This can be very suffocating for queer people, especially queer Sikhs, who are taunted for their traits. If you are a boy, you are often teased that you are acting like a girl and asked to man up. Similarly girls would be reminded to be within boundaries, and are burdened with safeguarding the honour of the family, all very patriarchal notions.

RR: What was your first experience of discrimination? Have you ever been bullied in school?

SS: This is a difficult question to answer. Discrimination because of which identity? I carry multiple identities, and in each of my identities I am a minority. So do you mean discriminated against because of my religion, or my sexuality? As a kid, growing up in West Bengal, I was often teased because of my religious identity by other kids, especially when I would shampoo and have my hair untied. They would question my gender, because I had long uncut hair, and boys are supposed to have short hair. Some would also think of my kara as a bangle.

I was very good in studies and was the first boy of my class, and I never faced any kind of bullying in school. I suppose I am cisgendered so my sexuality was not so obvious. College was a little different. There was a lot of stereotyping. I studied in a national level college, where students from all over India has joined after giving entrance exam, many from small villages and remote parts of India. For them, the fact that I was a Sikh person from Bengal was something funny. They were so small minded that they thought all Sikh people only live in Punjab. The fact that I did not fit into a macho Sikh man's image (I was very thin) added to their confusion, often making me the butt of jokes. But I think my college in general was a very bad place. Then when I came out, I was the only out gay person in college, and then again, I faced a barrage of questions. Some outrageous suggestions about how to change my sexuality, and then there were many rumors about me too. There was this one specific incident that happened with me, after I left college. I was living with my college friends in a shared flat in Gurgaon, and sharing a room with one of my batchmates. After a month or so, because he wanted the room to himself, he made an issue of my sexuality and said he will not be sharing a room with me. That was very hurtful for me.

RR: How was it when you stepped into the queer community?

SS: When I stepped into the queer community, I was all rosy eyed, and thought this is where I would be finally accepted fully. But that was far from the case. I soon discovered my Sikh identity was not acceptable to many, and I would be rejected as soon as they would get to know I was a turbaned Sikh. And I am talking pre-smartphone era, or when smartphones were still a novelty and apps like Grindr were yet to be made.

JAH: I have realized a fascinating phenomenon here in the Canaries and it is that LGBTQ+ Catholics have reappropiated the discourse and they are 
occupying certain spaces and spheres that were once neglected. Even Drag Queens perform dressed up as the Virgin Mary or Jesus Christ and young Catholics are also creating new support groups that are inclusive towards the community. Do you know of any similar situation within Sikhs?

SS: Outside of India, in some of the countries like United Kingdom, Canada or the United States with a larger Sikh diaspora, I know that there are support groups and that they are bringing up these discussions around religion and sexuality. They are also helping their members to accept both identities. We are at a very key point where we are either moving into a more accepting and inclusive interpretation of sex and faith or having a very rigid interpretation.

RR: How do you deal with all your identities?

SS: I have never had any issues with my multiple identities. They are all part of me, and I think it is wonderful that I carry so many different identities within me. It is in fact other people who seem to be having confusion or problems accepting that a person can have so many different identities at the same time. People like to box others in neat identities, and since they cannot do that to me, they have a problem.

RR: How was the reception of Sab Rab De Bande (We're all God's Creation)?

SS: The reception of $S a b R a b$ De Bande has been extremely good, right from the start when word about the project got out. Our crowdfunding campaign achieved its goal in under two weeks. There is a lot of excitement and anticipation for the movie. And the initial press reviews too have been positive. The movie is also getting selected at many different film festivals.

RR: How was it for you to produce this documentary? What was the most difficult part of producing it?

SS: It was extremely close to my heart, and I wanted to make this documentary for a long time. But it was also a very challenging one. This is my first documentary, and I had no experience of weaving the stories of different people together into under 30 minutes. Also, I did not have any sponsor or anyone, it was all self-funded in the beginning.

The biggest challenge for me was finding queer Sikh people who were willing to come on camera and share their experience. Amolak was the first one who came onboard. He had seen a call from me on Facebook, and he reached out to me. We had a long chat, and he said that this is an important topic and we should be bringing our stories to the public. But after that, it was a long search. A few people who were in fact out to their family or close circles, initially agreed, but later backed out. I kept a look put for people on social media and would reach out to them if I thought they had a story to tell. I would even assure them that we will keep their identities hidden, but even then, people were scared. So, over the next 2-3 years, I finally met and connected with people who agreed to be a part of the documentary.

Even when they agreed, none of them were comfortable to shoot at their home or workplace, because even if they were out to family, it was not a topic that their family was comfortable with. Also, time was another issue. I was in a full- time job, and so was my videographer, and the subjects of the 
documentary. So, finding a day and time when everyone would be available was a huge task in itself. And even when we did manage to take out time, we would only have 2-3 hours with them, and we had to shoot everything within that time frame, take all necessary filler shots. Also, given that it was self-funded, I was looking for people in or around Delhi so that the travel costs are a minimum.

RR: Did you get satisfied with the result of the documentary? Was it that you had in mind?

SS: Not sure if I can say that I am satisfied, but yes, I am happy with the final output. This is the story that I wanted to tell the world. Also, with all our constraints, both monetary and otherwise, I did the best I could, and I am happy with the output. There were different aspects of being a queer Sikh that I wanted to cover, and I have been able to cover them through these five stories.

RR: Why do not Ekampreet and Puneet show their faces in the documentary? Were they afraid of retaliation? Was it difficult to find people to participate in the documentary?

SS: As I mentioned above, it was extremely difficult to find people for the documentary, and that is one of the chief reasons why it took me four years to complete it. Both Ekampreet and Puneet had reservations about showing their faces, and I had to assure them that their identities will not be revealed. Ekampreet was not out to his family or anyone else (except may be a few close friends), while Puneet was very anxious of how people might behave with her if they got to know about her queer identity. It is not easy being a girl in Indian society, and being a queer woman exposes one to double the oppression and marginalization. She was very concerned about the judgmental attitudes and how it could affect her life and relationships. In fact, just when the documentary had completed and we were ready to submit to film festivals, Puneet had a kind of panic attack, and rang me up, asking to delete her footage from the documentary. I had to calm her up, and then further blur scenes where she appears to consider her concerns. This is the first time that queer Sikhs in India are openly discussing various aspects of their life and their religion. It is not easy to expose oneself like this, and on top of that, no one amongst us knows what the reaction of the Sikh society will be to this.

RR: The five testimonies in the documentary are arguing in favor of their both religious and sexual identities. Do you know anyone who gave up the faith in Sikhism because of their sexuality?

SS: Personally, I have not come across a queer Sikh person who gave up their religious identity or religion because of their sexuality. I have met quite a few gay Sikh men too, some even Amrithdari, who did not see their religious and queer identities in conflict, because of the larger message of acceptance and equality of Sikh religion.

JAH: Do you still face racism and stereotypes within the gay community? 
SS: Gay community is extremely racist from within. People often discriminate you because of your caste, they will not date you if you are not from a specific caste. So yes, I do face racism and stereotypes from within the gay community. Many a times people have it written in their profiles, "No Sikhs" or "No Sardars". Sometimes others go on a moral lecturing, and asking me not to be on dating apps, as Sikhs cannot be gay, or not to bring a bad name to Sikhs by being gay, or at least do not put your pics. On the other hand, some people use gay Sikhs on Grindr to satisfy their fantasies and I have been myself fetishized.

RR: How does queer Sikh deal with the religious leaders?

SS: I think key to changing attitudes is through dialogue and discussion. Unlike other faiths, there has not been a debate or discussion on the topic of homosexuality within the Sikh community. The religious leaders have always taken a reactionary stand, without trying to understand what homosexuality is, or what are the stories of queer people. For example, the Akhal Takh, whenever they have spoken on the topic, it has been in reaction to certain events, like the legislation of same-sex marriages in Canada, the 377 ruling in India.

It is important for the queer community to engage with them, highlight our stories and educate them on the topic as well. The more of us are out there, the more they see us as part of themselves. I am hopeful that Sab Rab De Bande will help bring these stories to the forefront and initiate a conversation.

RR: It is impossible not ask this question. How does caste operate in the queer community?

SS: Like most communities in India, queer community is not left untouched of casteism. A lot of casteist attitudes exist within the queer community, that are not discussed, or recognized or spoken of. Some people like Akhil Kang and Dhrubo Jyoti have been trying to address it and highlight the issues.

RR: Do you think that the colonial/LGBTIQ+phobic discourse of the granthi (priest) in the documentary will change in the future as the society and the new generation are slowly changing their mentality?

SS: Yes, I do think so. It is disheartening to listen to the granthi in the documentary, because much of what he says is out of ignorance and lack of knowledge on the issue. He equates homosexuality with depraved behavior and calls it unnatural, arguments that have no scientific evidence. Much of this attitude around the topic of homosexuality has been due to a colonial mindset, and so he sees the topic through the same lens. But he had no problem in accepting trans people, because in general there is some kind of acceptance of trans people in the society.

His interpretation of some of the things or verses from the Granth Sabib are coloured by his own homophobia, which in turn stems from ignorance and colonialism. With the younger generation being more open and liberal, I believe there will be a change in the future.

JAH: If the West's confrontation towards sexual dissidences is mostly of a long tradition of Christian perversion, I gather that within Sikh literature there are 
a number of sections that seem to raise Sikh's hopes, I mean for example that marriage is understood as a union of two genderless souls, as mentioned in the documentary. However, gender and sexual dissidences are still a tabooed and a very much controversial topic within the Sikh community. I wonder if Sikhism originated in a country that, prior to the European invasion, was relatively tolerant to other ways of being and loving, and your scriptures also reflect this diversity, what happened in the natural evolution of Sikhism?

SS: Every religion in India has been touched by Victorian morality and so we are very much influenced by those colonial thoughts. From there we have started interpreting our religion through a very colonial mindset, especially regarding homosexuality. Everywhere the British went you would find a law that is similar to section 377. That is why even ancient religions like Hinduism, where sexuality and gender was very much fluid, are not that accepting. When it comes to Sikhism, it has no such strict rules as it happens with Christianity, for example. Our emphasis is on spirituality and so inclusion comes naturally for Sikhs, but we are neither untouched by colonialism.

RR: Is gender/sexuality debate in schools/colleges/universities can help creating a more acceptable society?

SS: Without doubt! Gender/sexuality education in schools and colleges is the need of the hour, especially in a country like India. It will help bust many myths and taboos around the topic and dispel the lack of information/knowledge that often leads to a lot of homophobia. It will help youngsters understand their own feelings and educate them that sexuality is diverse and there is nothing wrong in being non-heterosexual.

JAH: I've been doing some research and I've ran into this YouTube channel (Logo) interviewing Sikh queer people and, although they are Americans, they were narrating that in June (Pride month) they mourn for the first weeks, in memory of those who were killed in Operation Bluestar, also mentioned at the beginning of your documentary. This certainly creates new bodies of queer Sikh culture, but do you know of any other peculiarities that are endemic to queer Sikhism?

SS: Young people in their early twenties on Instagram, or even Amolak Singh in the documentary, are very experimental with their looks and some of them even do drag. They carry both identities. Amolak, for example, is very strict about going to the gurdwaras wearing make-up and in this androgynous fashion. We do not let other define our identities.

RR: Puneet in the documentary states that "your religion is between you and your God" (00:26:44-00:26:48). Please make a comment on this assertion.

SS: Puneet makes a very valid assertion. Often we become too entangled in outward display of our religion, or bound by so many rules set by religious heads, on how one can reach god. But I think your faith is basically a personal relationship between you and God, and no one has a right to interfere and tell you what or how that relationship should be. 
RR: Government policy and legislation for LGBTIQ+ in India. What are the challenges?

SS: I think the biggest challenge right now is that we have a conservative government that is very anti-minority and anti-human rights. They were not very supportive when Section 377 case had come up in the Supreme Court. Even when they passed the Trans Rights Bill, they have discarded all suggestions and concerns of the Transgender community and come up with a law that is being vociferously opposed by the Trans community. I think it is not going to be easy.

RR: What is the Transgender Persons (Protection of Rights) Bill, 2019, situation now?

SS: The Bill was passed in the Parliament in Nov 2019, and has become a law. It was passed in the lower house in August while the Parliament was in chaos over Article 370 (the Article in the Indian Constitution that gave some special status to the state of Jammu and Kashmir), and then again in Nov 2019 it was passed in the upper house by a voice vote despite objection by many members and suggestions to send it to a Standing Committee. The Trans community has opposed the bill because of its many shortcomings. Despite many representations from the community, their concerns were overlooked and the government went ahead with its version.

RR: How is the pandemic affecting the queer community in India?

SS: The pandemic has affected the queer community the harshest because India has had the strictest and longest lockdowns. This had the most devastating effect on the trans community, many of whom depend on begging and sex work for their livelihood, were stripped of their earnings. Trans people do not have savings to fall back upon. Many of them are also taking hormones, some are HIV positive and need their ART medicines. It was a very dire situation, and in some states, the courts finally intervened and asked the government to provide them with pension or other help. Many trans activists too started crowdfunding campaigns to raise money to distribute essential supplies and ration to the member of the community.

Apart from that, many queer people had to return back home to their families and were then trapped with them. Many families are abusive towards queer children. This increased not just abuse, but also mental health issues. Further, even the ones who used to live with their families, they were not able to go and meet friends or hang out at community spaces. They lost their support system and this too adversely affected everyone. 
